ISSN 1518-3483

Licenciado sob uma Licença Creative Commons

(c) (1)

\title{
A expansão da Rede Federal de Educação Profissional, Científica e Tecnológica: os Institutos Federais em questão
}

\section{The expansion of the Federal Network of professional, Scientific and Technological Education: the Federal Institutes in question}

\section{Leandro Turmena $^{[a]}$, Mário Luiz Neves de Azevedo ${ }^{[b]^{*}}$}

[a] Universidade Tecnológica Federal do Paraná (UTFPR), Dois Vizinhos, PR, Brasil

[b] Universidade Estadual de Maringá (UEM), Maringá, PR, Brasil

\section{Resumo}

O objetivo deste artigo é problematizar sobre a expansão da Rede Federal de Educação Profissional, Científica e Tecnológica (EPCT), com a implementação dos Institutos Federais (IFs) no âmbito das políticas públicas e educacionais do governo Lula. Num primeiro momento, optou-se por investigar a historicidade e a configuração da Rede EPCT e, posteriormente, 
analisar os dados que refletem a materialização dos IFs no país, a partir de 2008. Considerase, mesmo se tratando de uma pesquisa em andamento, que o Estado, embora hegemonizado pela burguesia, não é absolutamente burguês. A educação também não é absolutamente expressão da vontade burguesa. Portanto, com a criação dos IFs, houve a ampliação da oferta de educação pública que, embora também inserida nos limites da sociedade de classes, constitui uma possibilidade de formação e desenvolvimento de "intelectuais orgânicos" comprometidos com a superação das relações sociais capitalistas.

Palavras-chave: Políticas Educacionais. Educação Profissional. Institutos Federais.

\begin{abstract}
The objective of this article is to discuss the expansion of the Federal Professional, Scientific and Technological Education Network, with the implementation of the Federal Institutes within the scope of the public and educational policies during the Lula government. First, we present the historicity of the Federal Professional, Scientific and Technological Education Network and, subsequently, we analyze the data that reflect the materialization of the Federal Institutes in Brazil, from 2008. It is considered that the State, although hegemonized by the bourgeoisie, it is not absolutely bourgeois. Therefore, with the creation of the Federal Institutes, there was an expansion of the offer of public education which, although also within the limits of class society, constitutes a possibility for the formation and development of "organic intellectuals" committed to overcoming capitalist social relations.
\end{abstract}

Keywords: Educational Policies. Professional Education. Federal Institutes.

\title{
Introdução
}

O texto aborda a expansão da Rede Federal de Educação Profissional, Científica e Tecnológica (EPCT), com a implementação dos 
Institutos Federais (IFs) no âmbito das políticas públicas e educacionais do governo Lula. Primeiramente, optou-se por investigar a historicidade e a configuração da Rede EPCT e, posteriormente, analisar os dados que refletem a materialização dos IFs no país, a partir de 2008.

Com o objetivo de captar detalhadamente a materialidade do objeto, a pesquisa, metodologicamente, segue os seguintes passos: a) Análise em fontes primárias: leis, documentos, dados coletados junto aos órgãos oficiais (Governo Federal, Ministério da Educação - MEC, etc.), referentes ao objeto de estudo; b) Pesquisa nas páginas eletrônicas dos Institutos Federais; c) Levantamento bibliográfico em obras clássicas, livros, artigos de periódicos, teses e outros materiais. O método de análise utilizado neste estudo é o Materialismo Histórico, pois, entende-se que a pesquisa deve apoderar-se da matéria, em seus pormenores, analisar suas diferentes formas de desenvolvimento e investigar minunciosamente a conexão íntima que há entre elas.

\section{Educação profissional, científica e tecnológica e a criação dos Institutos Federais}

No ano de 2006, a educação profissional e tecnológica passa por um novo processo de reestruturação a partir da iniciativa do MEC junto ao Conselho Nacional de Educação (CNE), decorrente do Parecer CNE/CES n ${ }^{\circ}$. 277. Haveria, neste contexto, a necessidade de uma reorganização dos cursos superiores de tecnologia, por poucos eixos tecnológicos e mais compactos, diante da organização por áreas profissionais definidas no Parecer CES/ CNE $n^{\circ}$. 436/2001 encontrar-se superada e não contribuir para o desenvolvimento industrial. No Parecer CNE/CES n ${ }^{\circ}$. 277/2006, os conselheiros reforçaram a importância da flexibilidade como sendo uma necessidade a ser conseguida a partir da interdisciplinaridade (AZEVEDO; COAN, 2013). 
Na data de 24 de abril de $2007^{1}$, o Decreto $n^{\circ} .6 .095$ estabelece as diretrizes para o processo de integração de instituições federais de educação tecnológica, para fins de constituição do Instituto Federal de Educação, Ciência e Tecnologia (IFET), no âmbito da Rede Federal de Educação Profissional, Científica e Tecnológica. Neste, foi delineado que os IFETs se caracterizam como instituições de educação superior, básica e profissional, pluricurricular e multicampi, especializadas na oferta de educação profissional e tecnológica nas diferentes modalidades de ensino, com base na conjugação de conhecimentos técnicos e tecnológicos às suas práticas pedagógicas (Art. $01, \S 2^{\circ}$ ). No que diz respeito à implantação dos Institutos, deve-se levar em consideração bases territoriais definidas, como dimensão geográfica e as características históricas, culturais, sociais e econômicas (Art. 01, $\S 3^{\circ}$ ).

Segundo este documento, a vocação dos Institutos é formar e qualificar profissionais para os diversos setores da economia, em estreita articulação com os setores produtivos e a sociedade (Art. $4, \S 1^{\circ}$, I), visando a consolidação e fortalecimento dos arranjos produtivos locais (Art. 4, $\S 1^{\circ}$, III), bem como estimular e apoiar processos educativos que levem à geração de trabalho e renda (Art. $\left.4, \S 1^{\circ}, \mathrm{IV}\right)$. Em relação à oferta de educação superior, objetiva-se formar profissionais para os diferentes setores da economia (Art. 4, $\S 1^{\circ}$, VII, a).

Neste sentido, no dia 12 de dezembro de 2007, o MEC emitiu a Chamada Pública MEC/ Secretaria de Educação Profissional e Tecnológica (SETEC) 02/2007, objetivando acolher, num prazo de 90 dias, propostas de constituição dos Institutos. Neste contexto foram elaborados e enviados à SETEC/MEC documentos dos conselhos da Rede: Conselho de Dirigentes dos Centros Federais de Educação Tecnológica (CONCEFET)

1 Nesta mesma data, o PDE contemplou a educação tecnológica e profissional através de três iniciativas: a) Reorganizar a rede federal de escolas técnicas, integrando nos Ifets; b) Novos concursos públicos e; c) Cidades-Polo: abertura de 150 escolas federais, elevando para 350 o número de unidades. O Plano também enfatiza que os Ifets são modelos de educação profissional e tecnológica (SAVIANI, 2009). 
(2007), Conselho das Escolas Agrotécnicas Federais (CONEAF) (2007) e o Conselho Nacional de Dirigentes das Escolas Técnicas vinculadas às Universidades Federais (CONDETUF) (2007). Em, 31 de março de 2008 a Portaria MEC/SETEC n 116 apresentou o resultado da Chamada Pública. Em junho de 2008, foi lançado o documento "Concepções e Diretrizes dos Institutos Federais de Educação, Ciência e Tecnologia" o qual está descrito a seguir. Em julho de 2008, o Poder Executivo apresenta ao Congresso Nacional o Projeto de Lei (PL) 3.775/2008 que propõe a instituição da Rede Federal de EPCT e a criação dos IFs.

Após o processo legal de discussões e articulações e, tendo em vista os princípios formuladores do PDE, no dia 29 de dezembro de 2008, via Lei $n^{\circ} .11 .892$, foi instituída a Rede Federal de EPCT, criando assim os Institutos Federais de Educação, Ciência e Tecnologia.

No site do MEC é apresentado o percurso histórico da educação profissional, técnica e tecnológica e o número total de 38 IFs, e seus devidos campi (primeira fase de expansão: 2008 a 2010), implantados em 2008. Ao longo das três fases (segunda: 2011 a 2012 e terceira: 2013 a 2014) de expansão, o número de campi aumentou significativamente, passando para um total de 580, entre estes, 74 são campus avançado, conforme Tabela 1.

Desta forma, pode-se questionar: Em que se fundamenta o modelo "Institutos Federais"? A implantação dos Institutos está vinculada a que demandas sociais?

Em junho de 2008, a SETEC elaborou o documento, versão impressa, intitulado "Instituto Federal de Educação, Ciência e Tecnologia: concepção e diretrizes". Em 2010, foi lançada a versão digitalizada deste documento com o título "Instituto Federal de Educação, Ciência e Tecnologia: Um novo modelo de educação profissional e tecnológica - concepção e diretrizes". Segundo o texto, a institucionalização dos Institutos é considerada pelo Governo como estratégia para o desenvolvimento local, regional e nacional e fortalecimento no processo de inserção cidadã de milhares de brasileiros, melhorando-lhes a qualidade de vida. 
Tabela 1 - Número de Institutos Federais, Campus e Campus Avançando por Estado

\begin{tabular}{|c|c|c|c|c|}
\hline & Instituto Federal & Campus & $\begin{array}{c}\text { Campus } \\
\text { Avançado }\end{array}$ & Total \\
\hline Acre & IFAC & 05 & 01 & 06 \\
\hline Alagoas & IFAL & 15 & 01 & 16 \\
\hline Amapá & IFAP & 04 & 01 & 05 \\
\hline Amazonas & IFAM & 14 & 01 & 15 \\
\hline Bahia & IFBA & 22 & 01 & 23 \\
\hline Bahia & IFBaiano & 14 & & 14 \\
\hline Ceará & IFCE & 28 & 03 & 31 \\
\hline Distrito Federal & IFB & 10 & 01 & 11 \\
\hline Espírito Santo & IFES & 21 & 01 & 22 \\
\hline Goiás & IFG & 14 & & 14 \\
\hline Goiás & IFGoiano & 08 & 04 & 12 \\
\hline Mato Grosso & IFMT & 14 & 05 & 19 \\
\hline Maranhão & IFMA & 26 & 03 & 29 \\
\hline $\begin{array}{l}\text { Mato Grosso } \\
\text { do Sul }\end{array}$ & IFMS & 10 & & 10 \\
\hline Minas Gerais & IFMG & 12 & 06 & 18 \\
\hline Minas Gerais & IFSuldeminas & 06 & 02 & 08 \\
\hline Minas Gerais & IFNMG & 09 & 02 & 11 \\
\hline Minas Gerais & IFSudesteMG & 07 & 03 & 10 \\
\hline Minas Gerais & IFTM & 07 & 02 & 09 \\
\hline Pará & IFPA & 17 & 01 & 18 \\
\hline Paraíba & IFPB & 15 & 03 & 18 \\
\hline Paraná & IFPR & 20 & 05 & 25 \\
\hline Pernambuco & IFPE & 15 & & 15 \\
\hline Pernambuco & IFSertão-PE & 07 & & 07 \\
\hline Piauí & IFPI & 17 & 03 & 20 \\
\hline Rio de Janeiro & IFFluminense & 09 & 03 & 12 \\
\hline Rio de Janeiro & IFRJ & 10 & 02 & 12 \\
\hline $\begin{array}{l}\text { Rio Grande do } \\
\text { Norte }\end{array}$ & IFRN & 18 & 02 & 20 \\
\hline $\begin{array}{l}\text { Rio Grande do } \\
\text { Sul }\end{array}$ & IFSul & 12 & 02 & 14 \\
\hline $\begin{array}{l}\text { Rio Grande do } \\
\text { Sul }\end{array}$ & IFRS & 16 & 01 & 17 \\
\hline $\begin{array}{l}\text { Rio Grande do } \\
\text { Sul }\end{array}$ & IFFarroupilha & 09 & 01 & 10 \\
\hline
\end{tabular}

(Continua)

Rev. Diálogo Educ., Curitiba, v. 17, n. 54, p. 1067-1084, jul./set. 2017 
(Conclusão)

Tabela 1 - Número de Institutos Federais, Campus e Campus Avançando por Estado

\begin{tabular}{lllll}
\hline & Instituto Federal & Campus & $\begin{array}{c}\text { Campus } \\
\text { Avançado }\end{array}$ & Total \\
\hline Rondônia & IFRO & 08 & 01 & 09 \\
\hline Roraima & IFRR & 04 & 01 & 05 \\
\hline São Paulo & IFSP & 32 & 06 & 38 \\
\hline Santa Catarina & IFSC & 21 & 01 & 22 \\
\hline Santa Catarina & IFC & 13 & 02 & 15 \\
\hline Sergipe & IFS & 10 & & 10 \\
\hline Tocantins & IFTO & 07 & 03 & 10 \\
\hline & Total & $\mathbf{5 0 6}$ & $\mathbf{7 4}$ & $\mathbf{5 8 0}$ \\
\hline
\end{tabular}

Fonte: Elaborada pelos autores a partir de: <http://redefederal.mec.gov.br/instituicoes $>$. Acesso em: 14 set. 2016.

O Estado entende os IFs na perspectiva de contribuição para o processo de modernização e desenvolvimento do país, qualificando (neste caso, com a educação profissional e tecnológica) os cidadãos e, consequentemente, incluindo-os no mercado de trabalho, levando em conta os arranjos produtivos e os aspectos sociais, culturais locais. O Estado atende, por um lado, demandas sociais da população, por formação e elevação dos níveis de escolaridade para adquirirem as devidas condições de empregabilidade e, por outro, as demandas do capital que exigem qualificação da mão de obra, objetivando o aumento da produtividade e a elevação das taxas de lucro.

As constantes mudanças - com ênfase na microeletrônica - no modelo de produção, vão provocando novas demandas para a formação dos trabalhadores. Há, segundo o documento, carência de trabalhadores qualificados no âmbito da educação profissional e tecnológica. Com base na pesquisa - "Demanda e perfil dos trabalhadores formais no Brasil em 2007", realizada pelo Instituto de Pesquisa Econômica Aplicada (IPEA), há uma a carência de profissionais qualificados. "O perfil da escolaridade média da mão-de-obra em falta no Brasil concentra-se nos trabalhadores com escolaridade média de 9,3 anos de estudos, o que traduz 
em trabalhadores que estejam cursando, no mínimo, o ensino médio" (BRASIL/MEC/SETEC, 2010, p. 32). Mesmo havendo uma tímida formação de profissionais pela modalidade de educação profissional e tecnológica, observa-se na realidade produtiva, o estabelecimento como exigência mínima de qualificação, o ensino médio completo. Neste contexto, "[...] a carência de mão-de-obra, em outros momentos históricos, sempre foi o mais forte elemento balizador da educação profissional e, portanto, definidor de política de ampliação de vagas para essa modalidade de educação" (BRASIL/MEC/SETEC, 2010, p. 33).

Portanto, defende-se a ideia, nos documentos oficiais, de que a construção de um país que busca sua soberania, que visa ultrapassar a condição de consumidor para a de produtor de ciência e tecnologia, passa pela ampliação das políticas públicas inclusivas, neste caso, a educação profissional e tecnológica. Nesse contexto, a atividade de pesquisa nos Institutos deve estar ancorada em dois princípios: o princípio científico (que se consolida na construção da ciência) e o princípio educativo (que diz respeito à atitude de questionamento diante da realidade). $\mathrm{O}$ documento aponta também que a formação do trabalhador, na e pela educação profissional e tecnológica, deve tornar o trabalhador um agente político, capaz de compreender a realidade e atuar na perspectiva de possibilitar transformações econômicas, políticas, sociais e culturais visando à superação das contradições existentes e a construção de outro mundo possível (BRASIL/MEC/SETEC, 2010).

Nota-se que há um esforço do Estado em ampliar a oferta de matrículas e interiorizar a educação pública federal, com a criação dos IFs e ampliação de campi, em Estados até então excluídos de efetivas políticas públicas em educação profissional e tecnológica.

O ideário nacionalista/modernizador, aliado à expansão do capital competitivo difundido nas décadas de 1930 e 1940, e a intensificação dos processos de industrialização-modernização e de monopolização, "[...] ao lado da emergência do populismo como instrumento de dominação das massas incorporadas à política, [...] que escapavam do controle das classes dominantes" (CUNHA, 2003, p. 171), e que definiram as 
políticas nas décadas de 1950 e 1960, voltam ao centro das discussões. A relação educação e desenvolvimento ganhou força nos discursos governamentais no contexto de implantação dos Institutos Federais, que são vistos como espaços estratégicos de qualificação da mão de obra visando ao desenvolvimento socioeconômico de diversas regiões do país. Sincronizar a educação com as necessidades do desenvolvimento econômico e social é o axioma da bandeira de modernização do país levantada pelo Estado.

O Diretor de Políticas da SETEC, Luiz Augusto Caldas Pereira (2013) afirma, naquela situação, que a retomada do crescimento econômico do país, vinculada a um modelo de produção que vincula intensa aplicação de ciência e tecnologia, gera a exigência de trabalho qualificado e eleva a importância da formação escolar e profissional em todos os níveis. Neste espaço cabe destaque a Educação Profissional e Tecnológica tornando necessária a expansão de sua oferta. Na ocasião, o Diretor de Articulação e Projetos Especiais da SETEC, Irineu Colombo (2013), destacou alguns fatores que embasaram a criação dos Institutos: a baixa qualidade científica da nossa formação educacional brasileira e a necessidade de fornecer base tecnológica para a economia e para o próprio sistema de educação, juntamente à necessidade de formar técnicos para o crescimento econômico que estamos vivenciando. Segundo o então Secretário de Educação Profissional e Tecnológica, Eliezer Pacheco (2013), a falta de trabalhadores qualificados ganhou destaque nas manchetes de jornais, foi tema de campanha eleitoral e se tornou numa espécie de fetiche de empresários e especialistas. "Como dizia o ex-presidente Luiz Inácio Lula da Silva, os prefeitos hoje em dia vêm a Brasília pedir escola técnica para os seus municípios e não mais uma universidade" (p. 01). No texto "Escolas técnicas e desenvolvimento”, Pacheco (2011 e 2013) afirma que a política neoliberal adotada pelo Governo de FHC provocou um sucateamento e privatização do patrimônio, prejudicando a economia brasileira. Neste contexto, universidades públicas e instituições federais de educação profissional e tecnológica foram desmanteladas, tendo seu funcionamento quase que inviabilizado. 
No governo anterior, inclusive, foi instituída a lei 9.649/98, barrando a criação de escolas técnicas federais. Não é por acaso que agora, quando o País consolida taxas de crescimento acima de 4\%, empresas encontram dificuldades para contratar mão-de-obra treinada e qualificada. A falta de técnicos é explicada pelo abandono e descaso que os governos passados tiveram com a educação profissional. No entanto, a concepção do governo Lula preconiza a valorização e o investimento pesado nas escolas técnicas (PACHECO, 2013, p. 01).

Outra manifestação a respeito da mesma matéria está presente na apresentação do texto de Silva (2009), destacando o foco dos Institutos, que é o de promover a justiça social, a equidade e a inclusão social com base num desenvolvimento sustentável, buscando soluções técnicas e gerando novas tecnologias: "Estas instituições devem responder, de forma ágil e eficaz, às demandas crescentes por formação profissional, por difusão de conhecimentos científicos e de suporte aos arranjos produtivos locais" (p. 08).

A afirmação de buscar "solucionar os problemas socioeconômicos em âmbito regional visando ao desenvolvimento", se destaca nos documentos oficiais e na legislação de criação dos IFs. Ao que parece, a criação e implantação dos IFs está atrelada ao fortalecimento e expansão das relações sociais capitalistas em regiões distantes geograficamente dos grandes centros urbanos. A expansão da EPT ocorre para expandir o capital para outras regiões e para a conquista de novas camadas intermediárias da classe trabalhadora. Segundo Brandão (2010, p. 80):

[...] seja através da (con)formação de mão-de-obra para as empresas que se instalam nessas regiões; seja através do oferecimento de pequenos serviços que nada mais são do que trabalho precário; seja através da inclusão de trabalhadores como consumidores; seja através da difusão - também regional - da graduação da educação profissional no setor privado.

As críticas elencadas nos documentos em relação ao governo de FHC podem ser entendidas no contexto do Estado neoliberal, adotado pelo governo anterior, que alavancou o processo de desindustrialização, 
privatização de empresas estatais, à mudança do padrão de inserção do país na economia globalizada (DAGNINO; RIBEIRO; CYPRIANO, 2011). Entretanto, é importante salientar que a política econômica adotada pelo governo Lula não se diferencia, na sua essência, da implantada por FHC.

Segundo os autores, a rede EPT, que surgiu entrelaçada ao projeto nacional-desenvolvimentista, com o objetivo de atender às demandas tecnológicas de formação de mão de obra qualificada para o processo de industrialização pela via de substituição das importações (governo Getúlio Vargas - 1930-1945), se expandiu e se consolidou historicamente. É nesse contexto, fruto de um pacto social que se estabeleceu entre os empresários nacionais e os trabalhadores da indústria, "[...] de que a qualificação da força de trabalho, por atender à demanda tecnológica dos primeiros e a expectativa de ascensão social dos segundos" (DAGNINO; RIBEIRO; CYPRIANO, 2011, p. 221) que se entende a criação e implantação da rede Rede Federal de EPCT e, por extensão, dos IFs.

Domingos Sobrinho (2013), referindo-se ao Decreto $n^{\circ}$.6.095, de 24/04/07, afirma que este foi editado sem prévio debate com a rede federal. Os Institutos foram uma novidade para a Rede de EPT, pois, anterior ao Decreto, a discussão que vinha sendo feita era a de transformar alguns CEFETs em Universidade Tecnológica Federal (UTF), como aconteceu no Estado do Paraná. Todavia, percebe-se, segundo o autor, o esforço do Governo Lula, no âmbito da educação profissional e tecnológica, em ampliar a Rede, rompendo com o projeto do Governo FHC — que a encarava como mero fator econômico, subjugada, assim, às necessidades do mercado e do mundo dos negócios - e, encarando esta modalidade de educação como fator estratégico para o desenvolvimento nacional e para o processo de inserção cidadã para milhões de brasileiros. Projeto este que se volta para as atuais configurações do mundo do trabalho, para a reinserção dos desempregados e desenvolvimento de programas integrados de escolarização/profissionalização, no intuito de atender o contingente de jovens e adultos sem alfabetização ou apenas com escolaridade parcial.

No contexto das discussões em torno da transformação dos CEFETs em UTF, Ciavatta (2006, p. 929) alerta, se referindo aos Institutos, 
para o fato de que "Destinados, originariamente, para as 'classes desfavorecidas', que continuam a procurá-los pelo vínculo da escola com o trabalho, a questão das classes sociais e a exclusão de tantos dos benefícios sociais são aspectos da realidade que não podem ser alheios à sua prática pedagógica".

A soberania dos países não advém apenas do poderio bélico para defender seu território, mas também da autonomia para produzir conhecimento e atender às demandas da população. Portanto, a educação é uma questão estratégica, tanto no nível básico para a educação de crianças e adolescentes, como no nível superior para o aperfeiçoamento profissional, científico e tecnológico de jovens e adultos, e para a produção do conhecimento que assegura a presença de um país entre as demais nações (CIAVATTA, 2003).

Assim, Pacheco, Pereira e Domingos Sobrinho (2010) consideram que a discussão sobre a relação ensino-ciência-tecnologia deve ser destacada no contexto do surgimento dos Institutos, pois se relaciona com as demandas do desenvolvimento nacional, no que concerne à formação dos trabalhadores, formação de sua cidadania e aos desafios do desenvolvimento da ciência brasileira.

As mudanças ocorridas no modo de produção capitalista, trazendo em seu bojo o avanço científico-tecnológico nos processos produtivos, implicaram na reorganização da educação profissional. Porém, este talvez seja um grande desafio. O ideário brasileiro de ser autossuficiente na produção de ciência e tecnologia, na condição de país de capitalismo dependente, enfrenta barreiras dos países do centro orgânico do capital, produtores e concentradores de maior parte de ciência e tecnologia produzidas pela humanidade, para delinear suas políticas de desenvolvimento científico-tecnológico e de uma educação ampliada para a ciência e as tecnologias.

Contudo, por que o Governo Lula estabelece uma reestruturação na educação profissional e tecnológica criando os IFs ao invés de UTF? Será que há maior demanda pelo nível de ensino técnico e profissionalizante e não uma significativa demanda pelo nível superior? 
Compreendemos a ação do Governo Lula em ignorar a Rede Federal de EPT, criando a Rede Federal de EPCT, num contexto de debates para a transformação dos CEFETs em UTF, na seguinte perspectiva:

Verifica-se na manifestação de conselheiros do CNE pela via normativa que é desencadeada a partir do MEC a persistência da venda do encantamento de uma condição de empregabilidade para os jovens da sociedade brasileira a partir da educação profissional de forma a aliviar o tradicional ensino superior público das constantes reivindicações de segmentos da base da sociedade e possibilitar a formação de uma força de trabalho de reserva o mais numerosa possível, contribuindo, desta forma, para o desenvolvimento econômico e social do Estado brasileiro capitalista, e aliviando pressões sociais, como a de por cursos de bacharelado. Foi nesse sentido que governos de matizes políticas diversas reformaram e normatizaram a educação profissional que se constitui como um ensino específico, focado e diversificado para atender expectativas diversas, àquelas dos setores produtivos e econômicos, assim como as de cunho social que buscam a conformação e o alívio de tensões na base da sociedade, que na contemporaneidade passam a ser rotuladas como inclusão, com o intuito de amenizar a situação de bolsões de miséria e pobreza que tenderiam a abalar estruturas sociais vigentes (AZEVEDO; COAN, 2013, p. 16).

Os IFs não foram pensados a partir da superação de uma apropriação educacional entendida como educação profissional e tecnológica com vistas à formação do ser humano, com base nos princípios da politecnia, visando à construção da emancipação humana do jugo do capital. Infelizmente, resultou numa educação escassa, para os "pobres e desvalidos da sorte", para que possam tentar se incluir na perversa sociedade de classes sob os ditames do capital (AZEVEDO; COAN, 2013).

Otranto (2010), problematizando sobre a criação e implantação dos IFs, destaca que este é um modelo alternativo à "universidade de pesquisa", que vem no bojo das reformas ocorridas na América Latina nos últimos anos, impulsionadas pelo BM. Estas reformas educacionais reforçam a ideia de criação de IES com custos financeiros menores aos das 
universidades, e a ênfase nos cursos de tecnologia a nível superior, pois, com caráter de maior flexibilidade, estariam mais integrados ao sistema produtivo e com menor custo, se comparado às universidades tradicionais.

O Estado brasileiro, se analisarmos os governos neoliberais, a partir da década de 1990, optaram pela lógica de "submissão consentida" (NEVES, 2005) aos ditames do capital internacional expressos na classe que mantém a hegemonia política e cultural no Brasil, sob o contexto de reestruturação produtiva.

\section{Considerações finais}

Considera-se que, com a implementação dos IFs, optou-se por ampliar a oferta de educação pública com uma "escola pública mínima/ enxuta", condição própria de um Estado que assume a característica de ser mínimo para as políticas públicas e sociais. Por esta ótica, as instituições federais que ofertam ensino superior não são exclusivamente as universidades de pesquisa, mas, contam com um modelo alternativo de instituições para a oferta de educação profissional, técnica e tecnológica.

Numa sociedade, como a brasileira, regida pelos princípios hegemônicos do capital, as políticas educacionais estão direta e indiretamente voltadas para o mercado e para o desenvolvimento capitalista, pois o Estado participa da reprodução do capital. Considera-se, entretanto, que o Estado brasileiro mesmo caracterizando-se como mínimo para as políticas públicas e sociais, não atendeu, somente à lógica do capital.

De acordo com Neves (2002, p. 219),

[...] o Estado, longe de se apresentar como gerência da classe dominante, afigura-se como condensação de relações de força entre classes e frações de classes. Mesmo com a ampla hegemonia da proposta burguesa de sociedade e de educação no Brasil nos dias atuais, o Estado, ao definir suas políticas, leva em conta os imperativos do capital em seu conjunto e também das outras classes sociais, e não apenas as demandas imediatas de um capitalista singular ou de fração do capital. 
Numa leitura dialética da realidade, entende-se que o Estado, embora hegemonizado pela burguesia, não é absolutamente burguês, também a educação não é absolutamente expressão da vontade burguesa. Portanto, na criação dos IFs, houve a ampliação da oferta de educação pública que, embora também inserida nos limites da sociedade de classes, constitui uma possibilidade de formação e desenvolvimento de "intelectuais orgânicos" comprometidos com a superação das relações sociais capitalistas.

\section{Referências}

AZEVEDO, L. A.; COAN, M. O ensino profissional no Brasil: Atender "os pobres e desvalidos da sorte" e incluí-los na sociedade de classes - uma ideologia que perpassa os séculos XX e XXI. Trabalho Necessário, Niterói/RJ, ano 11, n. 16, 2013. Disponível em: <http://www.uff.br/trabalhonecessario>. Acesso: 04 set. 2013.

BRANDÃO, M. O governo Lula e a chamada educação profissional tecnológica. RETTA. Rio de Janeiro, v.01, n. 01, p. 61-87, jan./jun., 2010.

BRASIL. Decreto n. 6.095, de 24 de abril de 2007. Estabelece diretrizes para o processo de integração de instituições federais de educação tecnológica, para fins de constituição dos Institutos Federais de Educação, Ciência e Tecnologia - IFET, no âmbito da Rede Federal de Educação Tecnológica.

BRASIL. Chamada Pública 02/2007. Chamada para a adesão das Instituições que compõem a Rede Federal de Educação Tecnológica aos IFs. Disponível em: $\langle$ http://portal.mec.gov.br/arquivos/pdf/chamada_publica_ifets3.pdf >. Acesso: 20 mar. 2012.

BRASIL. Portaria MEC/SETEC $n^{\circ} 116$ de 31 de março de 2008. Disponível em: <http://portal.mec.gov.br/arquivos/pde/ifets_chamada.html〉. Acesso: 20 mar. 2012. 
BRASIL. Projeto de Lei 3775, de 23 de julho de 2008. Projeto de Lei dos Institutos Federais de Ciência, Educação e Tecnologia. Disponível em: <http://www.camara.gov.br/sileg/Prop_Detalhe.asp?id=405479>. Acesso: 20 mar. 2012.

BRASIL. Lei $n^{\circ}$ 11892, de 29 de dezembro de 2008. Institui a Rede Federal de Educação Profissional, Científica e Tecnológica, cria os Institutos Federais de Educação, Ciência e Tecnologia, e dá outras providências.

BRASIL.(Ministério da Educação). OPlano de Desenvolvimento da Educação:Razões, Princípios e Programas. Brasília, 2007. Disponível em: <http://pde.mec.gov.br/> . Acesso: 29 abr. 2010.

BRASIL. Rede Federal de Educação Profissional, Científica e Tecnológica. In: <http:// redefederal.mec.gov.br/instituicoes >. Acesso em: 14 set. 2016.

CIAVATTA, M. Os Centros Federais de Educação Tecnológica e o ensino superior: duas lógicas em confronto. Educação e Sociedade, Campinas/SP, v. 27, n. 96 (especial), p. 911-934, out. 2006.

CIAVATTA, M. Universidade, pecado nativo. Carta Aberta. Trabalho Necessário, Niterói/RJ, n. 1, 2003. Disponível em: 〈http://www.uff.br/trabalhonecessario〉. Acesso: 04 set. 2013.

COLOMBO, I. Educação para um novo tempo: o Instituto Federal. Disponível em: $<$ http://portal.mec.gov.br/index.php?option=com_content\&view=article\&id=1 4428\&Itemid=874>. Acesso: 28 ago. 2013.

CUNHA, L. A. Ensino Superior e Universidade no Brasil. In: Lopes, E.M.T. et al. 500 anos de educação no Brasil. 3 ed. Belo Horizonte: Autêntica, 2003. p. 151-204.

DAGNINO, R.; RIBEIRO, N. M.; CYPRIANO, A. Reflexões para um debate sobre a orientação da rede dos Institutos Federais de Educação, Ciência e Tecnologia. In: BATISTA, E. L.; NOVAES, H. (Org.). Trabalho, educação e social: as contradições do capital no século XXI. Bauru/SP: Canal 6, 2011. p. 221-227. 
NEVES, L. M. W. Rumos históricos da organização privatista. In: NEVES, L. M. Wanderley (Org.). O empresariamento da educação: novos contornos do Ensino Superior no Brasil dos anos 1990. São Paulo/SP: Xamã, 2002. p.179-220.

NEVES, L. M. W. A sociedade civil como espaço estratégico de difusão da nova pedagogia da hegemonia. In: NEVES, L. M. W. (Org.). A nova Pedagogia da Hegemonia: estratégias do capital para educar o consenso. São Paulo/SP: Xamã, 2005. p. 85-126.

OTRANTO, C. R. Criação e implantação dos Institutos federais de educação, Ciência e tecnologia - IFETs. i. Rio de Janeiro, v.01, n. 01, p. 89-108, jan./jun., 2010.

PACHECO, E. M. (Org.). Institutos Federais: uma revolução na Educação profissional e Tecnológica. Brasília/DF, São Paulo/SP: Moderna, 2011.

PACHECO, E. M. (Org.). Enfrentando a fata de mão-de-obra. Disponível em: <http://portal.mec.gov.br/index.php?option=com_content\&view=article\&id=1 4428\&Itemid=874>. Acesso: 29 ago. 2013.

PACHECO, E. M. (Org.). Escolas técnicas e desenvolvimento. Disponível em: $<$ http://portal.mec.gov.br/index.php?option=com_content\&view=article\&id=1 4428\&Itemid=874>. Acesso: 29 ago. 2013.

PACHECO, E. M.; PEREIRA, L. A. C.; DOMINGOS SOBRINHO, M. Institutos Federais de Educação, Ciência e Tecnologia: limites e possibilidades. Linhas Críticas. Brasília/DF, v. 16, n. 30, p. 71-88, jan./jun. 2010.

PEREIRA, L. A. C. A formação de professores e a capacitação de trabalhadores da Educação Profissional e Tecnológica. Disponível em: <http://portal.mec.gov.br/index.php?option=com_content\&view=article\&id=14428\&Itemid=874 $\rangle$. Acesso: 28 ago. 2013.

SAVIANI, D. PDE - Plano de Desenvolvimento da Educação: Análise crítica da política do MEC. Campinas/SP: Autores Associados, 2009.

SILVA, C. J. R. Institutos Federais - Lei 11.982 de 29 de novembro de 2008: comentários e reflexões. Natal/RN: IFRN, 2009. 
SOBRINHO, M. D. Universidade Tecnológica ou Instituto Federal de Educação, Ciência e Tecnologia? Disponível em: <http://portal.mec.gov.br/index.php?option=com content\&view=article\&id=14428\&Itemid=874 > . Acesso: 28 ago. 2013.

Recebido: 07/06/17

Received: 06/07/2017

Aprovado: 22/07/17

Approved: 07/22/2017 